\title{
Cultura, prácticas de enseñanza y 'maneras de hacer' co- tidianas en una escuela rural uruguaya. Los escritos de un maestro-director (1929-1932)
}

\author{
Gerardo Garay Montaner*
}

\section{Resumen}

El artículo aborda el estudio de una experiencia educativa en el medio rural, en el Uruguay, entre los años 1929 y 1932; momento peculiar en el que se decidió su orientación pedagógica, condicionada por los impulsos de su director, Otto Niemann, un maestro recientemente titulado, proveniente del movimiento obrero revolucionario pero cercano al ambiente de renovación orientado por los partidarios de la 'escuela activa', en la línea del Dr. Ovidio Decroly. Problematizaremos la imagen de «director», como sinónimo de un funcionario supuestamente condenado a la pasividad y la disciplina. La lectura del Libro diario, a través de sus «ocurrencias» y «labores diarias», permitirá observar la acción creativa de su tarea pedagógica; los «ardides» para gestionar opciones en el contexto de sus posibilidades cotidianas. En definitiva, una poiética oculta y diseminada en las 'maneras de hacer'. Arte de escribir, de educar y arte de ser maestro.

\section{Palabras clave}

Método Decroly, cotidianidad, educación rural, pedagogía activa, Otto Niemann

Recepción original: 13 de mayo de 2021

Aceptación: 21 de junio de 2021

Publicación: 1 de julio de 2021

\section{Proyecto ilustrado y tradición obrera}

Nuestra sociedad global avanza a pasos de gigante, ¿por qué no alegrarse? ¿Acaso los enanos en hombros de gigantes no ven más lejos, tal como sugiere la famosa imagen proveniente del medioevo? ¿No eran gigantes Gargantúa y Pantagruel, los personajes de Rabelais, quienes representaban el deseo incontenible de la incipiente burguesía europea por saber más, por devorarlo todo, por embriagarse con los elixires posibles del conocimiento? ¿No fue la Abadía de Thélème, y su única regla: «¿Haz lo que quieras», la utopía pedagógica de los educadores modernos?

Sí y no. El sentido del crecimiento vertical, que nos proponen las imágenes de los gigantes y las metáforas de la nutrición, distan bastante de la excitación constante de hoy y de los estímulos narcotizados de las herramientas de la información. El proyecto de la llustración había puesto su esfuerzo en un crecimiento que poseía un sentido de emancipación: salir de la 'minoría de edad', romper con la tutela de las instituciones, con el fatalismo del cosmos; es decir, 'formar' un ser humano y proveerle las condiciones necesarias para su autonomía. La educación ocupó un papel fundamental; la referencia alimenticia se pobló también de imágenes agrícolas, tan antiguas como la acción de trabajar la tierra: hay que 'cultivarse'; educar es como cuidar una planta, decía Comenio: en la acción cotidiana no puede percibirse, pero la planta crece sin que poda-

$\left({ }^{*}\right)$ Profesor Asistente del Departamento de Historia y Filosofía de la Educación (FHCE-UDELAR, Uruguay). Dirección electrónica: gerardo.garay@gmail.com 
mos verla. Después del riego y del cuidado, en periodos de tiempo más extensos, será posible percibir sus frutos.

Este estandarte de la llustración, largamente acuñado y preparado en el viejo continente, pero precipitado en el último cuarto del siglo XIX en el Uruguay con una rapidez inusitada, está en crisis; es la moda. Como quedó evidenciado en un encuentro hace poco tiempo (Coloquio Nacional: La repetición escolar y sus clivajes. Aportes a la reflexión pedagógica. Montevideo, 14 de noviembre de 2018), buena parte de los docentes y profesionales de la educación, en el momento de referirse a la tradición educativa en este país, hicieron hincapié en la 'intencionalidad ideológica', 'intereses de clase', en la necesidad de fabricar un sistema cultural que justifique la 'selección' y explotación de una humanidad de 'primera', sobre una humanidad de 'segunda'. Las instituciones jugaron su papel, especialmente a través de la divulgación de conocimientos 'disciplinarios', 'clasificadores', 'universalistas', 'aristocráticos', 'jerarquizadores'; innecesariamente eruditos.

El problema fundamental de una visión tan simple, es que no logra tomar distancia de la idea tradicional que concibe a los procesos culturales como ya realizados; de una pieza, sin fisuras; obra de un grupo selecto de individuos y cuyo 'consumo' se realiza de 'una vez', sin la oposición de dificultades, resistencias y apropiaciones creativas.

Sin embargo, "somos herederos de un esfuerzo infinito»; esta hermosa expresión de Lucien Febvre (1970, p. 168), nos advierte de la tentación de fosilizar la comprensión de los acontecimientos históricos, desconociendo el largo y arduo trabajo de solidaridad colectiva que nos trajo hasta aquí, entre persecuciones y hogueras de libros y personas. También en el Uruguay el proyecto ilustrado se abrió paso en medio de dificultades; labor paciente de una sociedad orgullosa, autocomplaciente y segura de sí misma. La burguesía incipiente y los grupos de poder no tuvieron la exclusividad; a pesar de la escasa mención de la historiografía local, el mundo de trabajadores e intelectuales provenientes de la tradición obrera-revolucionaria, no estuvo absolutamente al margen y no siempre buscó ser una alternativa a las propuestas gubernamentales.

El caso de Otto Niemann (1888-1958) es representativo: obrero, autodidacta, ingresó al magisterio a una edad madura; su decisión de formar parte del sistema de educación pública-estatal, fue el resultado de un complejo proceso de discernimiento; desde una intensa actividad en una agrupación racionalista, que buscó apoyar la fundación de escuelas al margen del Estado (1911-1918), a asumir la dirección de una escuela agrícola, en el Departamento de Flores (1918-1923) y posteriormente en la 'Escuela Libre de Experimentación de Progreso', Canelones, Uruguay, (1924-1942). La literatura hasta el momento lo ha presentado como un maestro dedicado, defensor del método Decroly, militante en favor de la escuela pública y de la 'laicidad"1. Todo eso es cierto, pero no de ese modo. La parcialización temática de la vida y obra de Niemann no permite comprender su 'proyecto'; obra colectiva, además, que fue componiendo con paciencia, como los caracteres en la matriz, según la práctica del oficio tipográfico que lo acompañó toda su vida.

(1) Por ejemplo, el libro escrito por su hija Alba Niemann, maestra también de la Escuela de Progreso (1983) y Rossello (2007), exalumna. 


\section{Labores diarias de un director}

La investidura de 'director' de un centro educativo, es a menudo sinónimo de 'funcionario'; sujeto condenado a la pasividad y la disciplina; abulia pedagógica que responde a un orden jerárquico y una cadena de mando. Su labor, garantizar la continuidad de la institución: dar cuenta de la asistencia del personal, el cumplimiento de horarios, planificaciones, la revisión de la orientación pedagógica, el cuidado en el control de la asistencia de los estudiantes, sueldos que pagar, documentos que deben ser completados, etc. El objeto que sintetiza esa rutina es el Libro Diario; con él, una obligación: escribir como sólo un funcionario debe hacerlo: 'Faltó la maestra tal...'; 'Recibí de la inspección el documento...'; 'Se dio alimento...' etc. La base material, rudimentaria, es un soporte idéntico a tantos otros; un cuaderno de tapa dura proporcionado por las autoridades de Instrucción Primaria; en la parte superior reza: «ocurrencias y labores diarias»; doscientas páginas en blanco para ser escritas en un mes o un año, ¿qué importa? mientras no queden días en blanco o se descubran omisiones graves.

La escritura es una práctica encarnada en gestos, espacios y costumbres; un dispositivo que vehiculiza intenciones e intereses. ¿Por qué Niemann escribió febrilmente en un libro que posiblemente nadie leyera? Cerca de dos mil páginas en un periodo de trece años (1929-1942) nos hace pensar que su escritura no fue la satisfacción exclusiva de un requisito laboral. Niemann no escribió para las autoridades. Podría juzgarse natural, ante un emprendimiento pedagógico que daba sus primeros pasos, que la escritura fuera un testimonio de lo actuado. Niemann, sin embargo, escribió varios artículos y se sirvió de entrevistas y conferencias para dar cuenta de ello. La escritura del Libro Diario venía a colmar una necesidad distinta: la afirmación como 'autor' de una obra colectiva, que no le pertenecía absolutamente, pero en la que cobraba sentido su vida como hombre, obrero, intelectual y maestro.

Roger Chartier ha advertido que «no existe texto fuera del soporte que lo da a leer [...] y no hay comprensión de un escrito cualquiera que no dependa de las formas en las cuales llega a su lector» (1992, p. 55). Las formas producen sentidos, pero además, la utilización, la 'ocupación' -diríamos- de este espacio destinado al cumplimiento de obligaciones funcionales, fue un lugar de 'uso' privilegiado para Niemann. Reflejo interesado por supuesto- de la 'cotidianidad' de una escuela; ese lugar, al decir de Certeau, «sembrado de maravillas», cargado de microespacios de resistencias y libertades (2000). Pero también, la inversión de un rol (director) y de una actividad (escribir); movimiento que buscó hacer funcionar el orden vigente en un registro distinto. Los 'ardides' para gestionar opciones en el contexto de sus posibilidades cotidianas, son, en definitiva, una poiética oculta y diseminada en las 'maneras de hacer'. Arte de escribir, de educar y arte de ser maestro.

Este artículo entonces, aborda el estudio de una experiencia educativa en el medio rural entre los años 1929 y 1932; momento peculiar en el que se decidió su orientación pedagógica, condicionada por los impulsos de su director, Otto Niemann, un maestro recientemente titulado, de sólida formación racionalista, en el sentido inspirado por Ferrer i Guardia y por el ambiente de renovación orientado por los partidarios de la 'escuela activa', en la línea del Dr. Ovidio Decroly.

La importancia viene dada además porque tenemos una vía de acceso a la cotidianidad de una escuela, a través de la escritura del Libro Diario; la relevancia historiográfica está dada porque es posible hacerse una idea más cabal de los procesos de gestación 
de esa labor pedagógica y de la maduración intelectual de su director. Captar los momentos creativos de la producción intelectual, los ensayos y tanteos previos, las dudas, los conflictos personales y las condiciones materiales en las que se llevaron adelante esos emprendimientos, permite complejizar las opiniones petrificadas de las que hablábamos, tal vez alentadas por textos historiográficos en el que las ideas son presentadas como productos consolidados y cerrados sobre sí mismos y no como voces que interactuaban con un ambiente y un auditorio específico de referencia.

\section{La Escuela de Progreso y su director}

La Escuela de Progreso había sido fundada el 5 de julio de 1899 como Escuela Rural N. ${ }^{\circ}$ 11, y funcionó en paraje Puente del Colorado; en 1906 se trasladó a Progreso por falta de alumnos (Palomeque, 1992). Otto Niemann se hizo cargo interinamente de la dirección de la escuela, el 18 de setiembre de 1924 (LD, 30/IX/1924)2. Niemann obtuvo la efectividad como resultado del concurso llevado a cabo los días 25, 26 y 27 de marzo de 1926 (LD, 28/III/1926). En la Ley de Presupuesto de 1928, se estableció autonomía técnica y ciertas ventajas presupuestales, denominando «Escuelas Experimentales» a la escuela de Progreso, la escuela de Las Piedras (su director era Sabas Olaizola) y la Escuela de Malvín, fundada en 1927 y dirigida por Olimpia Fernández.

Niemann tuvo que 'defender' desde el comienzo su libertad de acción; un artículo de 1927 refiere el proceso que llevó a que en 1925 se declarara a su centro como «Escuela Libre de Experimentación» (LD, 31/x/1925). Su propósito, aunque resulte paradójico, era explicar el significado de la denominación, debido a «la necesidad de corregir falsas interpretaciones» (Niemann, 1927a, p. 228). El inicio tuvo que ver con una conferencia dada en Montevideo por el educador colombiano Agustín Nieto Caballero (18891975), acerca del éxito obtenido en su país, al frente de escuelas que habían adoptado el método Decroly. El impacto fue importante; inmediatamente se formó un «movimiento en favor de la Escuela Activa» (Niemann, 1927a, p. 228). La comisión de propaganda estuvo integrada inicialmente por Sebastián Morey Otero, Blas S. Genovese, Alberto Larrobla, Sabas Olaizola, Clemente Estable y José P. Bellán; Niemann fue invitado a integrarla en segunda instancia.

Sabas Olaizola y Niemann, sin embargo, estuvieron convencidos desde el primer momento en que las acciones no debían limitarse a hacer propaganda; era necesario realizar un «ensayo práctico» en las escuelas públicas. Una serie de malentendidos demoró las gestiones de esta Comisión, pero finalmente, Luisa Luisi (seguramente reeditando el antecedente de 1901 de Vaz Ferreira), presentó un proyecto en el que se autorizaba a algunos directores de escuela a experimentar en «programas, horarios y métodos».

Los directores debían presentar sus proyectos (había únicamente dos cupos) y no tendrían más contralor que la del Inspector Técnico, con carácter informativo ante el Consejo, concediéndose para ello una libertad de acción por tres años. No había dema-

(2) Utilizaremos la sigla 'LD' para referirnos al Libro Diario de la Escuela № 11 de Progreso, actual Escuela № 204, Canelones, Uruguay. El paginado de este documento es omitido debido a que el periodo de actuación de Niemann está compuesto por un corpus de ocho libros, cada uno de ellos numerados desde la página 1 a la 200. La indica-ción de la fecha exacta permitirá a un lector interesado corroborar las citas sin dificultades. 
siado mérito; Niemann refirió que después de transcurrido un año, acabaron por adquirir los elementos básicos para el funcionamiento de una escuela «normal». Sin embargo, el precio de la libertad bien lo valía:

[...] por el proyecto de la señorita Luisi obteníamos todo lo que nos había parecido difícil: librarnos de posibles interrupciones de parte de funcionarios, bien intencionados pero ajenos a nuestro plan, y obteníamos la libertad absoluta para optar por el método de nuestra predilección, y, además, la gran ventaja de proponer el personal. (Niemann, 1927a, p. 229)

Por el desarrollo de estos sucesos, explicó Niemann, era evidente que «[...] el título Escuela Libre no significa la ejecución de un método determinado, sino la libertad para el maestro de ensayar el método que crea más apropiado». No obstante, el proceso de Sabas Olaizola en Las Piedras, fue tempranamente orientado en una dirección precisa. El 14 de setiembre de 1925, inmediatamente después de otorgada la autorización gubernamental, declaró: "Se inaugura esta Escuela, empleando el Sistema de los Centros de Interés y bajo la técnica de los Programas de ideas asociadas del Dr. Ovidio Decroly» (Pirotto, 2012, p. 20). Niemann, en cambio, buscó no restringirse a una metodología previamente estipulada y decidió continuar buscando el camino más apropiado, aunque inspirado, entre otros, en los postulados de la tradición obrera revolucionaria que hizo de la «educación integral» uno de sus principales postulados:

El director de la escuela urbana de Las Piedras, se tomó la libertad de ensayar el método Decroly, tal cual lo aconseja su autor. Y yo, como director de la escuela rural de Progreso, me tomé la libertad de continuar ensayando, con mayor amplitud, procedimientos activos, sobre la base de una educación integral y adaptados al medio rural en que mi escuela se desenvuelve. (Niemann, 1927a, p. 229) ${ }^{3}$

Esta situación, en la génesis de los proyectos de la escuela de Las Piedras y la de Progreso, muestra una diferencia importante como ejercicio de libertad de sus directores. En 1927 Niemann pensaba que otras escuelas asumirían el mismo rango y en ese sentido, deseaba que todas fueran distintas y que en ellas pudiera observarse prácticamente «las ventajas de todos los métodos posibles y conocer las ideas personales de cada maestro, sin espíritu de competencia» (1927a, p. 230). Hermoso proyecto que no tendrá seguidores; Niemann terminará aceptando definitivamente el método Decroly, en circunstancias excepcionales, el 11 de agosto de 1932.

\section{Maestras-obreras}

El itinerario puede observarse a partir de 1929; su preocupación inicial tuvo que ver con la necesidad de evitar improvisaciones en las labores manuales, para el óptimo resultado en la labor educativa, pero también para cuidar la imagen ante la mirada de las constantes visitas a la escuela (LD, 15/iv/1929 y LD, 31/v/1929). La falta de un plantel docente preparado para asumir el desafío, va a ser uno de los temas recurrentes. Entre las dificultades en el plantel de maestras, habría que enumerar, en primer lugar, la formación profesional recibida, que hacía de los métodos tradicionales de enseñanza (exposiciones orales y aplicaciones abstractas), lo usual y el mecanismo más cómodo asumido como rutina. Hacia fines de 1929, Niemann se quejaba de los pocos avances en esta materia, especialmente en el personal más antiguo:

(3) En otro artículo de la misma época se definió a sí mismo como «un experimentador de la educación integral» (Niemann, 1927c, p. 64). 
La enseñanza activa no se impone si no es con vigilancia y la intervención mía. Sobre todo en el personal más antiguo, no se nota la formación de hábitos nuevos: por el contrario, dejando andar, se vuelve al punto de partida. Lo que no se olvida son los «asuntos básicos» sobre los cuales edificamos nuestra enseñanza. Pero esto se hace en forma puramente teórica: se hace ortografía, dictado y copia sobre esos asuntos; se hacen problemas y se dibuja, etc. sin otra fuente que el enunciado de la maestra, la conversación y la lectura. Y esto es contrario a mis propósitos. (LD, 14/VIII/1929)

En una conferencia dada bajo los auspicios de la Sociedad de Pedagogía, el 20 de enero de 1927, Niemann manifestó al auditorio que uno de sus objetivos para el próximo año lectivo consistía en «continuar mejorando la organización del establecimiento, dando unidad a la acción del personal»; en su opinión, este desafío era de «verdadera trascendencia», sin el cual «no adquiere consistencia ningún método, ningún programa» (1927b, p. 257).

Hacia 1930, el panorama no era más auspicioso; Niemann señaló que en los casos de maestras que no se «posesionan de esta nueva forma de trabajo», hay que recordar a cada paso lo «acordado», realizando una verdadera «persecución» (LD, 8/xI/1930). Si el esfuerzo por llevar adelante una escuela activa, inserta en su ambiente, requería urdir la trama con dos hilos diferentes: «la cultura media de los habitantes» y «la cultura media, laboriosidad y fuerza ideológica de los maestros» (Niemann, 1927b, p. 257), era evidente que estaba faltando parte importante de la materia prima. No había posibilidad de triunfo sin una «unidad de acción», expresada en una «unidad ideológica», que lejos de constituir uniformidades, formasen una escuela en la que «la verdad sea la única preocupación» (1927b, p. 258).

Un segundo impedimento para el desarrollo de la enseñanza activa era la carencia en algunas maestras de dos aptitudes importantísimas: en primer lugar, la aptitud de "ser prácticos», es decir, de saber trabajar y pensar los conocimientos en función de diferentes actividades, especialmente las agrícolas. Los trabajos manuales implicaban un compromiso fuerte con las tareas, fabricando velas, en la carpintería, desnatando la leche, criando pollos, fabricando manteca, trasplantando, etc.; pero el trabajo y las observaciones empíricas eran el escalón ineludible que sustentaban las lecciones teóricas. Al carecer de preparación y vocación para el trabajo manual, una tendencia habitual en algunas maestras, malinterpretando la orientación del «plan», era la de «usar temas locales para abordarlos sólo teóricamente» (LD, 14/x/1929). Por otra parte, algunas maestras carecían de iniciativa personal, sin la cual «no es posible resolver los infinitos problemas que se presentan y menos, orientar eficazmente la formación de la personalidad del alumno» (LD, 27/xI/1930).

Los artículos de Niemann en los inicios de la década del 20 estuvieron orientados a analizar y especialmente prescribir el tipo de maestros que se necesitan para forjar la «escuela del porvenir». Es interesante que haya tomado como modelo la figura del «obrero». El maestro debe actuar como el obrero fuera del taller; en el horario de trabajo, generalmente trabaja sin voluntad bajo un régimen de vigilancia; pero una vez finalizada su jornada, "se convierte en un trabajador incansable y desinteresado por un ideal de redención». Fuera del taller, el obrero busca desesperadamente instruirse, actuar en conjunto en una obra solidaria, que permita acercarse a una vida mejor, buscando su libertad y la del conjunto de la sociedad. Nosotros, los maestros, reflexionaba Niemann, no tenemos dos actividades distintas - «una, forzada, para nuestro sostenimiento y otra, voluntaria, para el ideal». Tenemos una sola tarea, «y en ella está la lucha por la vida» (Niemann, 1923, p. 286). 
Veremos cómo las preocupaciones de la vida cotidiana de la escuela de Progreso no rondarán en discusiones ligadas a estos grandes ideales.

\section{'Asuntos básicos' y 'centros de interés'}

Una vez declarada la Escuela de Progreso como Escuela Libre de Experimentación en 1925, Niemann no modificó sustancialmente la labor que venía realizando, centrada en los «asuntos básicos»; "algo así» como «centros de interés» (LD, 14/VIII/1929). Pero el estudio de los diferentes temas del currículo se hacía «en torno de actividades locales productivas»; es decir, los denominados centros de interés de los niños, estuvieron siempre supeditados a los «intereses sociales» (Niemann, 1927c, p. 64), que no eran otra cosa que las actividades productivas de la región:

\section{La Escuela Activa no es una concepción teórica que pudiera estar impregnada de un espíritu ajeno al de nuestro ambiente. Ella no puede actuar, si no es con nuestro niño y sus necesidades; no puede referirse, en su punto inicial y concreto si no es a nuestro país con todos sus problemas característicos. (Niemann, 1935, p. 1)}

Si bien Niemann nunca fue partidario de falsas oposiciones y a los diferentes asuntos buscó abordarlos desde el punto de vista de su contribución a una mejor educación, en el Libro Diario, sólo excepcionalmente encontramos el término «centros de interés», de indudable ascendencia decroliana, antes de 1932.

La idea de experimentación y de estricta libertad por parte de las docentes para buscar los mejores mecanismos para el aprendizaje, no fue simple retórica. La construcción del «plan» de trabajo de la escuela y sus fundamentos pedagógicos fue un largo proceso de realización colectiva. No todas las maestras supieron entenderlo o compartieron enteramente esta manera de proceder, sintiéndose muchas veces inseguras por falta de un plan rigurosamente demarcado. Niemann estaba convencido de la inutilidad de un método adoptado teóricamente, sin que surgiera de las necesidades del ambiente en el que se insertaba la escuela. Por supuesto, no renunció a ciertos 'fundamentos', o 'ideas básicas', que defendió vehementemente y que podrían sintetizarse en la frase: «Necesidad de dotar a cada individuo la aptitud para adquirir el conocimiento [...] lo que no es lo mismo que 'dar el conocimiento'» (LD, 3/v/1930). Para Niemann la «escuela activa» era aquella que «trabaja, ejercita la observación y el análisis sobre bases reales, sin sujeción a métodos y sistemas fijos»; por esto, el éxito dependería más bien de los maestros que de los programas. Era necesario un «espíritu nuevo», frase predilecta de Niemann que asume de la lectura de Ferrière (LD, 2/IX/1930).

La escuela debía, más que «formar» a los niños, «hacer que se formen» y para esto, era necesario proveerlos de un ambiente en el que puedan "ver cosas» $y$ «acciones» a su alrededor. Pero para que realmente esas cosas y esas acciones contribuyeran a que «se formen» los alumnos, era de primera condición que el maestro conociera la importancia de las cosas y supiera hacerlas conocer. Por último, el docente debía saber utilizar esos conocimientos provechosamente para «sugerir» en el que observa, la «necesidad» de la imitación y luego de la perfección, ya que «el material no es el que hace sólo el milagro, como muchas veces se cree, sino que consiste en saberlo emplear produciendo interés y actividad» (LD, 8/V/1930). Una vez asegurado esto, serían los niños quienes natural y espontáneamente actuarían, atraídos por la utilidad, la belleza y el deseo «moral» de vivir de acuerdo a los principios de la verdad (Niemann, 1922b, p. 153). 
Todas las actividades útiles «sirven», advierte Niemann, si les sumamos la actitud constante de «penetración»y «asociación de ideas». Por eso, insistirá constantemente en defender la libertad de las docentes, priorizando, antes que la asunción del «método mejor», cuestión siempre relativa, la búsqueda de una implementación variada y ajustada a cada situación. A esto lo llamó, actuar con «inteligencia»:

[...] es preferible que [el maestro] sea inteligente [...], y pueda aplicar elementos de un método, de diversos métodos o crear otros personales, según las circunstancias. Necesitamos, a este respecto, la máxima libertad, dejando por sentado, que necesariamente debemos adoptar todos los procedimientos que concurran a la formación de los resultados propuestos. (Niemann, 1931a)

Otras prácticas buscaron fortalecer directamente la expresión a través de la lectura y la escritura; por ejemplo, se traían recortes de periódicos y revistas y se las pegaba en una cartelera; generalmente los estudiantes debían elaborar informes sobre diferentes temáticas de la realidad nacional e internacional. Según una exalumna, estos ejercicios mostraban a los estudiantes que «cada uno podía instruirse sólo» (Rossello, 2007, p. 26). Todas las situaciones eran motivo de reflexión, lectura y escritura, Niemann nunca subestimó la capacidad de comprensión de los estudiantes, avivando constantemente su fascinación por aprender. Con ocasión del fallecimiento del expresidente José Batlle y Ordóñez, por ejemplo, aprovechó la «oportunidad», para leerles a los alumnos de $5^{\circ}$ año los comentarios de los periódicos El País y El Día -antagónicos desde todo punto de vista-; la contraposición no fue inocente, Niemann destacó

\begin{abstract}
[...] la serenidad y la altura con que ambos órganos periodísticos comentaron el hecho necrológico. A la vez hicimos lenguaje con palabras y frases. Hice un ligero recorrido por nuestra historia desde la iniciación de nuestra independencia hasta nuestros días, hablando de presidentes, revoluciones y constitución; y de los dos períodos en que está dividida la historia de la independencia: desde 1830 a 1904, período de las guerras civiles; de 1905 hasta la fecha, período de paz. Exhorté a los alumnos a investigar y razonar las ideas y las obras de los hombres, desapasionadamente, porque en todos los casos hay ideas generosas que impulsan, en mayor o menor grado. Estudiar las ideas ajenas no quiere decir aceptarlas y estancarse, sino igualarlas y superarlas (LD, 21/x/1929)
\end{abstract}

En otra oportunidad colocó un buzón en el patio de la escuela, «en el que podrán echar toda la correspondencia que quieran dirigirme», las cartas debían estar bajo sobre y podían ser firmadas o simplemente utilizar seudónimos (LD, 7/VII/1931); lo importante era participar, opinando, sobre el rumbo que la escuela iba adquiriendo. Para eso era fundamental «elevar la cultura»; en agosto de 1931, Niemann dirigió una circular a todos los padres, preguntándoles sobre la educación que estaban teniendo sus hijos en la escuela. Pudo percibir en las devoluciones, un alto índice de analfabetismo; la respuesta no se hizo esperar y organizó inmediatamente cursos nocturnos para mayores de 14 años de forma gratuita (LD, 13/IX/1931)4.

El combate a la ignorancia, comenzando por el analfabetismo, fue una obsesión en Niemann; denunció una práctica habitual, la de las familias «pudientes» que criaban niño/as huérfanos o desamparados en sus casas, en condiciones serviles. En este sentido, las maestras debían asumir una actitud celosamente ejemplar:

(4) Los cursos se realizaban dos veces por semana y comenzaron con 8 inscritos (LD, 14/X/1931). Semanas después, los estudiantes subieron a 13 y se sumaron varias mujeres (LD, 28/x/1931). Hacia el mes de noviembre, el número de asistentes subió a 19 (LD, 13/xI/1931), constatando que «es interesante el deseo que se nota de aprender y ampliar» (Niemann, 1931b). 
A la Sra. [una maestra de su escuela] le pregunté por una niña analfabeta, que está en calidad de sirviente en casa de su hermana y por un niño analfabeto que está empleado en casa de su madre, junto con quien vive ella misma, y éste me respondió, en síntesis, que no tenía nada que ver con lo que hacen la hermana y la madre, pues ella tiene ahora hogar aparte. Yo, por mi parte, rechazo este criterio, no tanto porque sea hermana e hija, sino porque es maestra, y maestra de la escuela a la que deberían concurrir esos analfabetos en edad escolar. No quiero dejar más que constancia del hecho, sin ampliar con los comentarios que el caso me sugiere. (LD, 1/VIII/1931)

Niemann no descuidó en ningún momento el aprendizaje académico; entre «trabajo» y «cultura» no había oposición. A pesar del temor de los padres, que reclamaban para sus hijos una instrucción que no podían adquirir fuera del ámbito de la escuela, logró mostrar sus conquistas en ese campo (LD, 30/XI/1929) ganándose el respeto de sus vecinos al demostrar que las actividades laborales en la escuela, estaban lejos de reproducir las condiciones de servidumbre del ambiente local. La formación de la «inteligencia» del niño, no se oponía a la adquisición de conocimientos efectivos en todos los campos, disciplinarios, enciclopédicos, universalistas; pero requería invariablemente la prohibición para el adulto de «no enseñar nada, que no sea demostrado»; axioma inclaudicable del espíritu antidogmático que impregnaba la escuela y la figura de su director: «Recalqué la importancia de no imponer ideas de ningún género. En todos los casos en que los hechos dejen dudas sobre el resultado, es preferible que dejen esas dudas, antes que erigir una afirmación que no demuestra ser claramente la verdad [...] De parte del maestro debe haber mucha sinceridad» (LD, $11 / \mathrm{VIII} / 1930)$. No es humillante para el maestro no saber, «siempre que, naturalmente, después de la duda suceda la investigación y después del ignorar siga el deseo de aprender, formando esa corriente entre el alumnado» (LD, 8/IX/1930).

\section{Problemas edilicios}

El 27 de agosto de 1931, la Escuela de Progreso recibió la visita de la pedagoga Amélie Hamaïde (1888-1970), por entonces, la segunda responsable de la escuela de L'Ermitage, institución insignia del método Decroly. Hay detalles de la referencia de Niemann que muestran que los vínculos con el ambiente «decroliano» en Uruguay, no eran del todo fluidos y que el cuestionamiento radicaba en los escasos «efectos» que estaba produciendo la escuela de Progreso.

La señora Hamaïde visitó Progreso en compañía de Olimpia Fernández, directora de la Escuela Experimental de Malvín y estudiante directa de L'Ermitage (LD, 27/VIII/1931). Niemann se mostró molesto porque la visita fue varias veces aplazada; cuando finalmente se concretó, hablaron personalmente en alemán, pero inmediatamente se lamentó que «la conversación principal [tuviera] que hacerla con auxilio de Fernández, en francés» (LD, 27/VIII/1931). No obstante, la calidez de la pedagoga belga, causó buena impresión:

\footnotetext{
Nuevamente pude constatar en la Srta. Hamaïde a la persona sencilla y comprensiva, a la maestra idealista y de acción [...] me ha honrado doblemente, por haber partido de ella el interés por conocernos, lo que es poco común, pues generalmente los visitantes suelen ir a donde los llevan y los que llevan suelen elegir lo más efectista, sin reparar que lo esencial de una escuela no está «siempre» en las exterioridades. Según la Srta. Hamaïde, lo que más le interesaba conocer de nuestra escuela era su espíritu; y en cuanto a él, díjonos, estaba plenamente satisfecha. (LD, 27/VIII/1931)
}

La cordialidad fue recíproca, ya que, según el testimonio de Niemann, Hamaïde «manifestó hallar una interesante orientación», sólo opacada por la falta de comodidad, impedimento para la obtención de mejores resultados (LD, 31/VIII/1931). 
La Escuela de Progreso era una escuela rural, sus inmediaciones presentaban un aspecto de deterioro importante. A instancias de Niemann, que integró una Comisión de Fomento Vial, iniciativa privada que nucleó a parte de las «fuerzas vivas» de la localidad, se iniciaron en 1929 tareas de acondicionamiento de los caminos que costeaban la Escuela con la ayuda de un grupo de vecinos, "con bueyes, palas y arados» (LD, 24/IV/1929).

Algunos de los espacios pensados como aulas eran de piso de tierra, extremadamente húmedos e imposibles de utilizar los días de lluvia. Todavía en 1932, debían convivir dos clases en cada salón, lo que «hace imposible el trabajo activo porque falta espacio para el movimiento» (LD, 22/VIII/1931). La convivencia entre estos grupos no era sencilla y requerían de una coordinación precisa: mientras unos ejecutaban trabajos en voz alta, el otro grupo debía realizar actividades en silencio (LD, 19/II/1932).

Otro impedimento para «hacer escuela activa», relata Niemann, era la estrechez del horario escolar y las dificultades de transporte, especialmente la de las maestras, que en su mayoría viajaban en tren desde Montevideo y debían adaptarse a la reducida oferta de horarios (LD, 17/VIII/1932).

Queda pendiente desarrollar una investigación -como lo ha sugerido Antonio Romano- que estudie las asignaciones presupuestales a las tres Escuelas Experimentales y corroborar si existieron discrepancias fundamentales. Son evidentes los datos que indican la molestia de Niemann con la Comisión Administradora; después de ocho años al frente de la Escuela, habló de «apoyo excepcional» de parte de las autoridades escolares (Niemann, 1931a), de una situación «que se agrava día a día» (LD, 30/VII/1930), al punto de que «no estamos en condiciones de teorizar ni de pensar en éxitos brillantes» (LD, 28/x/1931).

No había, sin embargo, lugar a excusas; Niemann exigió en todo momento, un compromiso optimista y sin claudicaciones: «[...] todos sabemos -o debemos saberque únicamente sobreponiéndonos a las adversidades y poniendo buena voluntad, podremos conservar el entusiasmo que emanará de su trabajo hecho a base de confianza y de la seguridad de que se da lo mejor que las circunstancias permiten» (LD, 28/x/1931).

Un compromiso que exigía más imaginación y dedicación por parte de las maestras, algunas de ellas, una vez más, preocupadas en «nimiedades» y en generar un «semillero permanente de discordias» (LD, 19/iii/1932).

\section{Las dificultades del 'plan'}

Si repasamos las experiencias alternativas, al menos en el ámbito del movimiento obrero revolucionario, podríamos identificar claramente una constante: la centralidad descollante de los educadores responsables y las dificultades para encontrar un cuerpo docente preparado, que sostuviera y profundizara las convicciones pedagógicas. La libertad de espíritu de Niemann, capaz de experimentar sin temores, tuvo un acompañamiento significativo en varias maestras -entre las que se encontraba su hija, Alba- pero no en otras, que cumplieron un rol importante en el período que estudiamos, y que van a servir de detonante, para otras decisiones de importancia en la vida escolar. 
En 1930, Niemann reflexionaba sobre la necesidad, -que describía como característica de los docentes de su tiempo- de otorgarles el «programa» confeccionado, como si de «muletas» para andar se tratase. Y esto, no por pereza o incapacidad, sino por el hábito de recibir las cosas hechas. La situación tuvo su importancia cuando Niemann se empecinó en demorar la presentación del plan general de la Escuela, hasta que llegara el día en que cada maestro se sintiera capaz de preparárselo, «pudiendo yo apreciar cómo cada uno lo concibe» (LD, 25/111/1930).

Esta estrategia no fue percibida de igual manera por parte del personal, y especialmente una maestra, a quien nombraré «AS» que, en virtud de una acumulación de situaciones $s^{5}$, terminó presentando una queja a la Comisión Administradora, devenida en sumario ${ }^{6}$. Es interesante notar que en las declaraciones de AS -información que nos llega a través de los apuntes de Niemann en el Libro Diario- se saque poco en limpio respecto al funcionamiento de la escuela y sus métodos, exceptuando la percepción de que en la Escuela de Progreso, «las maestras no saben qué hacer por falta de programa» (LD, 10/vilI/1932).

En el Libro Diario consta que en el correr del año 1931 se realizaron varias reuniones de personal dedicadas al estudio y evaluación del plan de trabajo educacional. En noviembre salió a la luz un artículo con el título «Nuestras ideas se difunden» (Niemann, 1931c). En él se narraba el éxito de acogida de las ideas directrices del plan educacional; publicadas en el número anterior, fueron reproducidas y «acompañadas de elogiosos conceptos» por la revista de estudiantes Ariel, por el órgano oficial del Centro Protección de Choferes «Auto Uruguayo» -el editor responsable, Cristóbal Otero, un conocido anarquista, lo había visitado poco antes, junto al pedagogo argentino Julio Barcos- (LD, 29/VI/1931), y por el diario del Partido Socialista El Sol.

Es interesante que el título escogido hiciera uso del pronombre posesivo en primera persona del plural, mostrando el sentido de pertenencia de las ideas ensayadas en la Escuela y no como una simple aplicación de ideas ajenas. Más adelante se referirá de este modo: «[...] Nuestro plan es el resultado de una prédica, no es ocasional, es el resultado de una norma establecida hace muchos años» (LD, 10/VIII/1932).

(5) Entre ellas, podemos contar en primer lugar el hecho de que el «espíritu» de la escuela activa requería un esfuerzo importante en el trabajo de las maestras y en ese sentido, una exigencia mayor que la de cualquier docente en una escuela «común». Niemann lo explicitó en todo momento y, como advertencia, formó siempre parte de los acuerdos básicos de trabajo. En este sentido, la vigilancia y exhortaciones para mejorar la enseñanza por parte del director fueron constantes, al punto de que, en opinión de AS, las maestras son «víctimas de un régimen terrible» (LD, 14/III/1932). Por último, el hecho de que trabajase con él su hija, Alba Niemann, fue motivo de queja en más de una maestra, mostrando molestia por presuntos tratos «preferenciales» por parte del Director. Esto fue desmentido por Niemann, que llegó a realizar, por su cuenta, una encuesta al personal (LD, 15/III/1932).

(6) El primero de abril de 1932 Niemann recibe una notificación: debía abandonar el cargo de Director mientras la Comisión Administradora realizara la investigación pertinente, en base a los cargos presentados por AS. Se nombró una Comisión Investigadora que tomó declaraciones en la Escuela y retiró, para su estudio, los Libros Diarios. La Comisión estuvo integrada por el Inspector Regional Sr. Alberto Alves y el secretario de la Comisión Administradora, junto a cuatro vecinos, «invitados para hacer acto de presencia y testificar declaraciones» (LD, 5/IV/1932). Veintisiete días después, Niemann asumió nuevamente el cargo, pero indirectamente, se enteraba que la maestra AS también se reintegraría al trabajo. No hubo resolución. La molestia de Niemann se hizo notar, debido a que, en su opinión, no gozaba de la potestad de elegir el personal como los demás directores de Las Piedras y Malvín (LD, 28/IV/1932). A esta altura de los acontecimientos, Niemann juzgó que el personal estaba definitivamente fragmentando en «maestras de conciencia» y un "personal opositor» (LD, 22/VII/1932). 
Mientras tanto, y como una cuenta más en un largo rosario de desacuerdos, el 10 de agosto de 1932 la Comisión le exigió a Niemann «concretar en un programa la orientación de esta Escuela». Al parecer, las ideas básicas publicadas y propagadas meses antes, no habían colmado las expectativas de los miembros de la Comisión (LD, 10/vilI/1932).

Las razones por las cuales «todavía no se había cerrado definitivamente nuestra experiencia con un programa rígido», no fueron atendidas. Estamos en el día 10 de agosto de 1932, a casi una década desde el comienzo de la libre experimentación en la Escuela de Progreso, un largo trabajo de desgaste con algunos vecinos, con las autoridades escolares y con parte del personal. Se corría el riesgo de tirar todo por la borda. Niemann consultó una vez más al personal; esta vez, les preguntó si consideraban que su trabajo se basaba en un plan orientado y si eran conscientes de lo que hacían. Parecía una broma pero no lo era. El resultado fue ampliamente satisfactorio; conjuntamente con las respuestas de los padres, consultados anteriormente y apoyado en las crecientes muestras de apoyo a nivel nacional e internacional, declaró: «Más que programa, hemos tenido siempre reuniones constantes y demostraciones prácticas de los procedimientos que he querido adoptar [...] la situación actual alcanzada por nuestras experiencias es para nosotros un triunfo y no tememos más que a la falta de sinceridad» (LD, 10/VIII/1932).

Las presiones administrativas, en cambio, los recortes de presupuestos y las intrigas internas hicieron su desgaste. Al día siguiente, Niemann convocó una nueva reunión de personal para anunciar un significativo cambio de táctica; gestualidad política entre el espacio de los condicionamientos y sus resistencias: de ahora en más se asumiría un único método; el método Decroly:

\begin{abstract}
Pero como siento también yo la necesidad de concretar, para extraños y especialmente las autoridades escolares y para imponer al personal normas precisas, para que no se preste esa falta (supuesta) a interpretaciones y actividades que no colaboran con la obra escolar. Dije, pues, que el método definitivo adoptado es el Método Decroly. Haciendo una reunión de nuestra obra, hice notar cómo toda ella está inspirada en la orientación biológica de ese método. Los centros de interés fueron por nosotros modificados en cuanto a los puntos de partida. En vez de los llamados intereses del niño, tomamos los intereses sociales o las actividades productivas de esta región, con lo cual obteníamos todas las ventajas del método con la atención central en el trabajo productivo. Para conservar ese punto de partida encontré siempre la dificultad, en parte del personal, que no siempre se hallaba dispuesto a practicar y a conocer en sus fuentes mismas las referidas actividades. No pudiendo contar con la posibilidad de reorganizar el personal para continuar insistiendo, he resuelto detenerme aquí, porque con el método dicho, puedo llenar perfectamente mi propósito de hacer una enseñanza adecuada al medio en que actuamos (LD, $11 / \mathrm{VIII} / 1932)$
\end{abstract}

No había rupturas ni claudicaciones; por un lado, el ajuste general de acuerdo con Decroly, consistía en adoptar plenamente el método que principalmente les había servido de guía y orientación y, por tanto, no iba a ocasionar a las maestras ningún trastorno. Se trataba fundamentalmente de un nuevo ordenamiento, asociándolos a los intereses del niño en vez de las actividades productivas. Resultaba poco creíble. «Por mi parte -aclaró Niemann-, adopto el método con entusiasmo»; pero en seguida matizó: «lo adopto con criterio amplio de sus cuestiones fundamentales, habiendo penetrado en sus prácticas sin hacer ostentación de ellas y sintiéndome atraído a las cuestiones básicas del método» (LD, 11/VIII/1932).

Lo/as lectore/as coincidirán en que esta decisión se asemeja más a un gesto exterior, producto del cansancio y de situaciones excepcionales, que al resultado de un convencimiento pedagógico. «Supongo, dirá Niemann, que nuestra resolución produci- 
rá el deseado efecto en la Comisión y en el Sr. Director de Enseñanza, quedando definitivamente deslindado el método seguido»; costos de la libertad (LD, 11/VIII/1932).

\section{Conclusiones}

Estamos demasiado acostumbrados a conformarnos con poco, especialmente en educación; por eso nos resulta extraña la figura de este director; sus gestos, vehementes, poniendo demasiada energía en asuntos que nos parecen sin importancia. Esta distancia de sensibilidad es oportunidad para el estudio historiográfico. En 1918, pocos meses después de haber obtenido el título de 'maestro' de enseñanza elemental, Niemann proyectó una conferencia sobre los ideales que debían orientar y regir el magisterio. Una crítica solapada le hizo desistir de la idea. Cuatro años más tarde -la obstinación era una de sus características- concretó su aspiración. El tiempo en el ejercicio de la docencia no otorgaba crédito suficiente, pero nadie podía afirmar que tomaba la palabra en nombre de principios abstractos, sin haber pisado la escuela. Lejos de apagar su entusiasmo, reafirmó su compromiso; la suerte de la humanidad está inexorablemente ligada al éxito que tengamos con nuestros proyectos educativos: «noto que una luz misteriosa me alumbra cada vez más, y que mi corazón late al unísono con los dolores y los placeres puros de la humanidad entera» (Niemann, 1922c, p. 41). Es la voz de un predicador más que la de un militante. Principios, ideales, pureza; pero la trascendencia no olía a incienso ni provenía de la mortecina iluminación de los templos; era el reflejo de la ilustración secular que impregnó a la sociedad europea desde el siglo XVII y que no dejaba de propagarse, extendiendo sus reivindicaciones a otros sectores sociales; por eso, un tipógrafo apenas adolescente, autodidacta, en este rincón del mundo, podía citar a Kant y sus ideas reguladoras en una revista dirigida a obreros, y concebir la educación como el único «factor de evolución» de la humanidad (Niemann, 1909). Actúa de tal modo que tus actos sean tomados como ejemplo por la humanidad entera, parecería decir su 'imperativo categórico'; por eso escribió con pasión en un 'libro' que pocos leerían.

Aunque tuviera la certeza de que nadie recorrería sus páginas, debía ser escrito de ese modo, refiriendo a cada paso las dificultades y logros de realización; una poiética apenas perceptible entre los intersticios del sistema: los conflictos personales, las fatigas de lidiar siempre con medios materiales insuficientes, la conciencia de que la producción cultural debe llevarse adelante desde el lugar en el que uno se encuentra, desestimando los 'centros' de irradiación. 'Tácticas' -en el sentido que otorgó de Certeau (2000, p. XLIX y ss.)- que permitió erigir un 'lugar propio' y 'ocupar' un nombre -el del 'método Decroly'- sin renunciar a las búsquedas que estaba teniendo lugar; procesos colectivos que debían salvaguardarse de intereses burocráticos y mezquindades individuales. Táctica también que llevó a Niemann a dejar de lado matices y diferencias con los proyectos de escuelas 'activas', para hacer frente común contra la escuela dogmática.

El soporte material en la que Niemann plasmó su escritura como director, nos da una clave para interpretar su labor pedagógica; las formas producen sentidos y la significación de este ensayo, -así le gustaba denominarlo Niemann- en la Escuela N. 11 de Progreso, en el periodo 1929-1932, es la orientación de una escuelita que se animó a producir sentidos nuevos; centro de irradiación y producción cultural en una zona condenada a la producción agrícola, sin otra aspiración que la reproducción material de la vida. Niemann ocupó ese espacio, para intentar transformarlo desde adentro, lidiando 
con las autoridades escolares, con las creencias compartidas de sus vecinos, con las rivalidades de sus compañeras de trabajo; con sus propias obstinaciones. No estaba solo; por sobre todas las cosas, Niemann fue un intelectual, pensó con cabeza propia y fue consciente del legado que recibía -entre sus citas más recurrentes encontramos a León Tolstoi y Rafael Barrett- tradición que le ayudaría a dar una respuesta creativa y creadora en el medio social específico en el que vivió.

Llegados a este punto, es necesario sospechar de algunas definiciones a priori: 'anarquista', 'escolanovista', 'laico', etc. y percibir más claramente la originalidad irreductible de su accionar. La Escuela de Progreso también es el producto singularísimo de un cúmulo de complejidades que no se constriñen a la figura de su director. Este 'ensayo' nos permite pensar las relaciones entre 'ideas' y 'realidad social' con otras categorías que no sean las de 'influencia' y 'determinismo'. En definitiva: las experiencias educativas, no son sencillamente la arcilla moldeada por las manos amorosas de sus pedagogos.

\section{Referencias}

Chartier, R. (1992) El mundo como representación. Estudios sobre historia cultural. Barcelona, Gedisa.

de Certeau, M. (2000) La invención de lo cotidiano 1: Artes de hacer. México, Universidad Iberoamericana.

Febvre, L. (1970) Erasmo, la Contrarreforma y el espíritu moderno. Barcelona, Martínez Roca.

Libro Diario (1924-1932) «Escuela», núm. 11, (actual núm. 204), Progreso, Uruguay.

Niemann, A. (1983) Otto Niemann, un maestro sin fronteras: La educación democrática en el Uruguay. Su significación en la primera mitad de este siglo. México, Penélope.

Niemann, O. (1909) «Los Anarquistas», El Surco. Año i, núm. 5, p. 1.

Niemann, O. (1912a) «Hacia nuestro perfeccionamiento». Educación Sociológica, año ii, núm. 5 y 6.

Niemann, O. (1912b) «Nuestro Momento». Educación Sociológica, año ii, núm. 7, pp. 1-2.

Niemann, O. (1914a) «Cómo se prepara la guerra, en el hogar, la escuela, el periodismo y la política». Infancia, año iii, núm. 30, pp. 1-2.

Niemann, O. (1914b) «La Escuela religiosa». Infancia, año iii, núm. 32, p. 3.

Niemann, O. (1922a) «Una Escuela Agrícola Modelo. La obra del maestro señor Otto Niemann». Anales de Instrucción Primaria, año xix-xx, Tomo xix, Notas escolares i, núm. 4, pp. 224-229.

Niemann, O. (1922b) «La libertad en la escuela ii». Educación, núm. 5, pp. 153-154.

Niemann, O. (1922c) «El ideal del maestro». Anales de Instrucción Primaria, año xix-xx, Tomo xix, núm. 1, 2 y 3.

Niemann, O. (1923) «La situación económica del maestro y sus consecuencias». Educación, núm. 20, pp. 286-291.

Niemann, O. (1927a) «Las escuelas libres». Educación, núm. 55, pp. 228-230.

Niemann, O. (1927b) «Ideas básicas sobre las que funciona la Escuela Rural de Experimentación Libre Estación Progreso (Canelones)». Anales de Instrucción Primaria, Tomo xxi, núm. 2, pp. 257-260. 
Niemann, O. (1927c) «Una reforma escolar no se puede aceptar ni rechazar sin un ensayo racional previo». Educación, núm. 57-58, pp. 64-65.

Niemann, O. (1931a) «El personal enseñante». La Colmena. Publicación periódica de la Escuela Experimental de Progreso, año iii, núm. 10.

Niemann, O. (1931b) «Curso de adultos». La Colmena. Publicación periódica de la Escuela Experimental de Progreso, año iii, núm. 10, 10.

Niemann, O. (1931c) «Nuestras ideas se difunden». La Colmena. Publicación periódica de la Escuela Experimental de Progreso, año iii, núm. 10.

Niemann, O. (1935) «Editorial». La Colmena. Publicación periódica de la Escuela Experimental de Progreso, año vi, núm. 14.

Niemann, O. (1944) «Lo que falta a la democracia. Párrafos de una conferencia sobre Rafael Barrett». Verdad, año 2, núm. 29, pp. 2-3.

Palomeque, A. (1992) Maestro Otto Niemann. Designación a la Escuela N. ${ }^{\circ} 204$ de Progreso, Departamento de Canelones. Montevideo, Cámara de Representantes, República Oriental del Uruguay, Comisión de Educación y Cultura, Carpeta N.ํ 2167, Repartido N. ${ }^{\circ} 653$.

Pirotto, E. (2012) «Bienes culturales que nos sorprenden». Quehacer educativo, núm. 114, Montevideo, pp. 19-26.

Rossello, C. (2007) Otto Niemann, maestro de maestros. La Paz, S/E. 


\section{Cultura, pràctiques d'ensenyament $i$ «maneres de fer» quotidianes en una escola rural uruguaiana. Els escrits d'un mestre-director, 1929-1932}

Resum: L'article aborda l'estudi d'una experiència educativa en el medi rural, a l'Uruguai, entre els anys 1929 i 1932; moment peculiar en què es va decidir la seva orientació pedagògica, condicionada pels impulsos del seu director, Otto Niemann, un mestre recentment titulat, provinent del moviment obrer revolucionari però proper a l'ambient de renovació orientat pels partidaris de la 'escola activa', en la línia del Dr. Ovidi Decroly. Es qüestionarà la imatge de «director», com a sinònim d'un funcionari suposadament condemnat a la passivitat i la disciplina. La lectura del Libro diario, a través de les seves «pensades» $\mathbf{i}$ «tasques diàries», permetrà observar l'acció creativa de la seva tasca pedagògica; els "ardits» per gestionar opcions en el context de les seves possibilitats quotidianes. En definitiva, una poiètica oculta i disseminada en les 'maneres de fer'. Art d'escriure, d'educar i art de ser mestre.

Paraules clau: Mètode Decroly, quotidianitat, educació rural, pedagogia activa, Otto Niemann.

\section{Culture, méthodes d'enseignement et «façons de faire » quotidiennes dans une école rurale uruguayenne. Les écrits d'un instituteur-directeur, 1929- 1932}

Résumé: L'article aborde l'étude d'une expérience éducative menée dans le milieu rural, en Uruguay, entre les années 1929 et 1932 - une époque particulière où l'on décide de son orientation pédagogique, conditionnée par les impulsions de son directeur, Otto Niemann, un instituteur récemment diplômé, issu du mouvement ouvrier révolutionnaire, mais proche de l'ambiance de rénovation orientée par les partisans de l'« école active», dans le sillage du Dr. Ovidio Decroly. Nous nous pencherons sur la question de l'image de "directeur", considéré comme un fonctionnaire soi-disant condamné à la passivité et à la discipline. La lecture du Libro diario, à travers ses "occurrences » et ses "tâches quotidiennes", permettra d'observer l'action créative de sa tâche pédagogique, ainsi que les «stratagèmes » mis en œuvre pour gérer des options dans le contexte de ses possibilités quotidiennes. En définitive, une poïétique cachée et disséminée dans les «façons de faire ». Art d'écrire, d'éduquer et art d'être enseignant.

Mots-clés: Méthode Decroly, quotidienneté, éducation rurale, pédagogie active, Otto Niemann

\section{Culture, teaching practices and daily «ways of doing things» in a Uruguay- an rural school. The writings of a master-director, 1929-1932}

Abstract: The article addresses the study of an educational experiment in rural areas in Uruguay, between 1929 and 1932. The experiment applied an approach to teaching proposed by its director, Otto Niemann, a recently qualified teacher with roots in the revolutionary labour movement but also close to the ideas of renewal supported by the 'active school', led by Dr. Ovidi Decroly. We challenge the conception of the "director" as an official allegedly doomed to passivity and discipline. Reading the Libro diario, and its 'ideas' and 'daily tasks', will help to shed light on the creative nature of its teaching, and its "tricks" for managing options in the context of the everyday possibilities. In short, a poetry hidden and disseminated in 'ways of doing': the art of writing, of educating and of being a teacher.

Keywords: Decroly method, everyday life, rural education, active pedagogy, Otto Niemann. 